'Their story is a hard road to hoe': How art-making tackles stigma and builds wellbeing in young people living regionally.

\begin{abstract}
Remote and regional Australia have comparatively fewer mental health services than their urban counterparts, what is more, mental health remains profoundly stigmatised.

Aim: to understand how, if at all, the process of group art-making then publically displaying the artworks can contribute to stigma reduction for young people experiencing mental health challenges in regional Australia.

Method: interviews with six young artists who use regional mental health services, and 25 people who viewed their displayed art utilising a thematic analysis of the coded interview data.

Findings: demonstrated how art-making as a process increased self-esteem, social interaction and artistic expression; whilst the viewers experienced an emotional connection to the art. The viewer's response enhanced young people's confidence in their abilities.

Conclusion: Incorporating art-making and exhibiting the art in public spaces could be incorporated into young people's mental health services to support wellbeing and inform the perception the general public hold of mental health, thus reducing stigma.
\end{abstract}

\title{
Introduction
}

Increasing recognition of mental illness, most notably anxiety and depression, as a major public health issue has led national and international public policies to place greater emphasis on improving the population's mental health status, particularly amongst young people (YP). The actions taken in response to this change in focus increasingly relies on a public health approach to tackling the determinants of health and in particular the stigma surrounding mental illness. The consequences of feeling stigmatised are well documented, and include, limiting a person's ability to attain and keep a job or safe place to live, reducing a person's desire to seek treatment and support, fears of not being accepted by family and friends or the larger community, and avoiding relationships and social activities (Stangl, Earnshaw, Logie, van Brakel, Simbayi, Barré, \& Dovidio, 2019). Stigma offers real challenges when supporting those YP with a mental illness both as part of the YP's journey of recovery and promoting good mental health and wellbeing in the wider community. 


\section{Background to the study}

Responding to the breadth of mental health needs of YP (aged 12-25) in regional Australia is challenging the capacity of both government and non-government sectors (Ivancic, Cairns, Shuttleworth, \& Welland, 2018). Access to mental health professionals decreases in line with remoteness while the prevalence of mental health issues is unchanged between urban, regional and rural settings (National rural health alliance 2017). Unsurprisingly given the comparative lack of resources those services that are offered are often narrow in their focus with very high rates of prescribed psychiatric medications across all age groups. Nearly $12 \%$ of the $15-24$ year age group received a mental health related prescription in 2017-18 (Australian Institute of Health and Welfare 2019), despite often having unconfirmed diagnosis due to their age, with overall prescribing rates being highest in service deprived regional Australia (Australian Institute of Health and Welfare, 2018).

Nationally, antipsychotic prescriptions for those under 17 years increased a further $8 \%$ in 2016-17 from pre-existing high levels (The Australian Commission on Safety and Quality in Health, 2017) suggesting upward trending of this treatment option for YP. Equally so the range of talk-based therapy options are also arguably narrow in regional Australia. Affordable Government funded therapies are overwhelmingly delivered within a mono disciple paradigm of psychology (Australian Government, 2019) predominantly aligned to Cognitive Behavioural Approaches (CBT) approaches and operating out of office spaces traditionally tailored for older adults rather than YP.

The need to add to this range of therapeutic inputs to regional YP is highlighted through understanding the complex interplay of social, developmental and psychological factors that figure prominently as active determinants of mental wellbeing for YP (Australian Institute of Health and Welfare, 2018). Very high regional youth unemployment (Brotherhood of St Laurence, 2018) low rates of high school completion and a low drive for 
upward social momentum have influential relationships with the young person's emergent identities (Breen, van de Werfhorst, \& Jæger, 2014) and how they view their worth and efficacy as a novice adult entering an adult world.

Low self-efficacy, self-worth and a reluctance to enter a mental health system that is socially constructed as having inherent stigma all act as significant impediments for unsupported YP to seek the help they require to have mental health assessment and input. Junge (2019) explained how social distancing or othering, creates stigma which manifests in loneliness and anti-social behaviour for those who feel stigmatised. In regional and rural context this stigma is worsened given the lower chances of anonymity offered in such sized communities and additional pressures to conform to social norms (National rural health alliance, 2017).

\section{Art -making in response to stigma}

Talking therapies use words as their primary means to structure and make sense of lived experience, yet words can often feel inadequate to convey depth of emotions. Edwards (2014) described how profoundly traumatic experiences and emotional states go beyond words, thus requires alternative modes of expression. 'Art as therapy' focuses on the act of art-making itself, where an immersion in the creative process is considered enough to support wellbeing (Kramer \& Gerity, 2000).

The area in which this research took place has a plethora of arts-based festivals, galleries and public art that demonstrate the diversity and creativity in the region. Creative Communities in Australia (McDonald \& Mason, 2015), highlighted how the creative arts can provide a bridge to belonging for populations in regional areas. A sense of belonging is essential in supporting the formation of social connections (Gentle, 2018), and can combat isolation and anti-social behaviours associated with mental health challenges (Junge, 2019). 
Bolwerk, Mack-Andrick, Lang, Dörfler, and Maihöfner (2014) MRI study findings

implied there is a correlation between art-making and resilience, or stress resistance, both important in reducing the impact of stigma. Art programs for YP have long been linked with improved motivation, self-image, hope for the future and self-esteem (Venable, 2005).

Furthermore, art programs have been described by WHO (2017) as one of the key building blocks towards sustainable, resilient communities. This was demonstrated in the work of Quinlan, Schweitzer, Khawaja, and Griffin (2016) where the process of art-making was found to decrease challenging behaviours and improve emotional responses in young refugees. Research by Duran Diaz (2018) found that art-making with young immigrants facilitated both social and cultural inclusion. As Jensen (2011) and Birhane (2017) highlighted, the social is an essential aspect of identity, which Corrigan (2014) has shown, can have a positive effect on combatting stigma.

The process of art-making has been shown to improve the mental health and wellbeing of YP through personal and social gain. This paper asks if both the process in 'art as therapy' projects, and the public showing of the art can reduce stigma and increase wellbeing for YP utilising mental health services in regional Australia.

\section{Materials and Methods}

The overarching aim of the project was to explore the impact, if any, of art to decrease self- and public stigma of YP with pre-emergent and emerging mental health challenges in order to promote help-seeking behaviours that underpin enhanced psychological safety. To achieve this aim the study initially utilised peer group based therapeutic art creation to enable reduction of self-stigma, and to build social networks for YP. The study then sought to build empathy and strength-based perceptions in the local 
community towards this population of YP by publicly displaying the art created by YP.

Positive public feedback was then communicated back to the young artists.

The overarching research questions guiding the study were:

1. What therapeutic gains, if any, were reported by YP as being experienced through the process of creating art in a peer group context?

2. What were the experiences of viewers of the publicly displayed art toward the worth and value of YP in their community?

3. How did YP respond to the public's feedback on their displayed art works?

\section{Ethics}

Ethics was approved by the Southern Cross University School of Health and Human Sciences Human Research Committee in 2018. The primary ethical issues were those pertaining to undertaking research with vulnerable populations, in this case YP with preemergent or emergent mental health issues. Separate participant information sheets were approved for YP and participating adults to ensure consent was fully informed for all. Parents or guardians approved consent for those too young to do so and data was de-identified for all study participants to ensure confidentiality (Kapitan, 2017).

\section{Data collection}

This was a three-stage qualitative study. Stage 1 occurred at two artist-lead art groups within mental health services attended by 12 YP interested in art-making in regional Australia where youth suicide, youth unemployment and need for youth services are all high (Social Atlas, 2016; South, 2006). In Stage 2 the art the YP created was displayed at a major retail outlet and community building alongside de-identified stories of recovery. Stage 3 was feeding back the experiences of the public who had been interviewed about the artworks to the YP. At each stage one-to-one semi-structured 10- 40 minute interviews were conducted 
and recorded to elicit in-depth personal experiences. The interviews were transcribed and

then subjected to thematic analysis. Stage One data was collected at the culmination of one holiday and one term-time art project where_six artists-agreed to be interviewed. Data collection for Stage 2 was held over two days outside a major retail outlet and at a community centre. Passers-by were asked if they would like to view and comment on artwork made by YP with mental health challenges $(n=25)$. Stage 3 data was collected from two of the participating artists three months after the exhibition as no other artists were available- those that were declined to be interviewed. See table 1 below

Data Analysis

Braun and Clarke (2006) approach to thematic analysis was used in the management and interpretation of the different data sets. In keeping with this approach, the researchers independently engaged in repeated immersive listening of the audio recorded semi structured interviews to identify meaningful experiences within the words and narratives of the research participants. It was not possible nor desirable to establish categorical distinctions at the onset of the analysis owing to the nature of the research. This not only allowed the researchers the freedom to be sensitive to emerging issues and key themes, it also increased the trustworthiness of the findings by reducing any potential biases that the researchers might have been harbouring. Initial qualitative codes were constructed from these with the researchers then searching for shared meaning between emergent codes to form themes of lived experiences in relation to the focus and aim of the study. The three researchers then convened to collectively determine mutually agreed themes in order to further strengthen the trustworthiness of the findings (Korstjens \& Moser, 2018).

\section{Findings}

Inevitably, there was some overlap between the stages of the study. To avoid repetition findings have only been included once, even if they have relevance to more than 
one of the stages. Presenting the themes in this way, it is argued here, offers the reader a better insight into the experience of those that took part and helps forms a coherent narrative account.

Stage 1

Theme 1: Forming a community of practice

This study shows that accessing art programs can support feelings of empowerment for YP through the forming of communities of practice, were members were treated as equals regardless of ability:

I could be freer-not a big deal, didn't over think because others helped make decisions. Our facilitator made it so it wasn't teacher-student but more like a mentorbut not a mentor-we all just came into one. Learning was informal rather than formal. We felt equally expert...we meshed (A1).

Theme 2: Agency and self-esteem

Agency and self-esteem grew as the participants engaged with the painting and drawing: "I could make a mistake and be comfortable with it"' then added: I didn't think this was something I could do. Coming out with other people was big for me. I was afraid and did it anyway. The art enabled a change- work with others come to the group. This was reiterated by A2: I could be freer- not a big deal, didn't over think because others helped make decisions. This showed how agency and self-esteem are related to social ease.

Theme 3: Social ease

Each artist had described how socialising was not easy for them but that having the art to focus on had helped. They explained that the process of art-making had made conversation flow more readily which had pleasantly surprised them.

'it's given me a bit more insight on working with other people-I'm not used to it'.

And, 
I learnt how to do new stuff and heard people's stories of the people in the group. Stories of everyday life whilst we made art. Felt like normal friends just chatting about stuff. The art helped-it's a good conversation starter- making art and chatting" (A2).

Stage 2

Theme 1: Previous lived experiences of mental illness.

18 of those interviewed had a lived experience of family members who had or continue to have mental health challenges. Those who approached the art display or agreed to view the art and be interviewed spoke of their experiences, overtly communicating empathy and positive constructions of YP:

The purple one with tree - everyone is in darkness, living in the shadows of other people and nobody is taking much notice of them. My daughter has mental health and a drug problem so you take her to mental health and they say it's a drug issues so you take them to the Drugs \& Alcohol people and they say its mental health problem. They all have wonderful gifts, beautiful gifts and make a contribution in their own right as we all have. They have a kind soul but are just lost...We judge first before we even accept them (V5).

This artwork is shown in Figure 1 below.

Theme 2: Experiences of emotional connection.

The majority of the participants interpreted the art, they spoke of experiencing an emotional

connection to the art and the artists through one or more of the publicly displayed works:

\begin{abstract}
... had me really sucked in, the one with the purple skull... the one with the rainbow face and the closed off mouth as I think that is how YP often feel, that they don't have a voice and one with the lady in pyjamas drinking coffee, she just looks like the perfect epiphany of someone who is relaxed but actually she is perplexed on the inside...I said 'wow'. It's fantastic, , in my experience I found that people with mental health issues are probably more creative and can bring emotion to paper and pen better than those who are not having things go on in their minds (V6)
\end{abstract}

Other viewers comments indicated understanding through emotional connection: "Distinct differences of the two artworks-one more disturbed-they must be more distressed in their
suffering compared to other that does not represent distress so much (V22). V23 stated: Wonderful they want to contribute. I feel more empathy for them, I can see their sadness (V23). Another responded with: Yes, the story is a hard rd to hoe. They are younger. Difficult to-looks like its self-loathing- or part of the artist-she is trying to decipher (V24)

Theme 3: Breaking down stigma. 

noted:

The stigma experienced by YP with mental illness can be countered by their art as V6

It gives an insight to what the person is going through. So rather than just seeing an itinerate person with scratches up their arm, cigarette hanging out their mouth hanging out the front of the mall if they saw what they were creating and what they were feeling on the inside, visually, in a visual summary I suppose, it gives you a different picture.. Stigma is still well and truly alive. As much as we say we are fighting stigma it is still out there. It is slowly getting better but it is still there especially with older people. So for YP to reach out for help it's generally to an adult person and they still have stigma to mental health. The views of adults can be a barrier to YP reaching out for help.

And,

V7 and V9 felt strongly about the medium and the stigma YPs feel:

I can't get over the talent of YP in this area... I think it really depicts, in a visual way what mental illness is like for YP. If we can work as a community to make YP feel sense of community come back again perhaps that would have a good impact on YP. If we can change the general idea of YP within the media and the general idea of what a young person is, that they're just scary delinquents, it becomes a self-fulfilling prophecy for them... they have so much potential but they just can't see it. The sense of achievement these YP would have coming down here and seeing their art work on display that would be just so amazing for them. It would be like 'wow, I did that and all these people are looking at it.

V23 commented: “ [I have] Admiration for the skills of the artists, beautiful work- represents the unknown. V 24 said: "The stories are very helpful in understanding the YP journey. Can identify with [their] journeys. Reminds that we have to talk about mental health and illness".

He added: "[It is] therapeutic to make art and for the people who look who can identify'that's just how I felt' I'm not alone- key to mental illness not feeling alone and not being blinkered (V25)

Stage 3

Themes: Agency, self-esteem, connecting 
When the art was displayed to the general public the artists had been amazed by the at my art (A2) and another reiterated that it had pushed them further with [their] art (A1). A1 had been surprised: It's good, makes me feel a bit better about what I'm doing [...] things that are a bit different. Confidence in their skills as artists had increased. A1 said Family always say that's lovely but you think is that what they are just saying or do they just want to make you feel a bit better? So hearing that is really good, it's really good (soft voice), makes me feel like it's actually good. The agency in what they represented of themselves was captured by A2 when she recognised that through the artwork People don't know who we are except what we allow them to know of ourselves. This had provided a sense of power and control on others perceptions of them.

In conclusion, findings from the $1^{\text {st }}$ stage included the themes 'forming a community of practice', 'agency and self-esteem' and 'social ease'. Findings from the $2^{\text {nd }}$ stage included the themes, 'Previous lived experiences of mental illness, experiences of emotional connection and 'breaking down stigma'. Themes from the $3^{\text {rd }}$ stage included, agency selfesteem, connecting. These are illustrated in Figure 2 below

\section{Discussion}

Stage 1 findings highlighted how the act of art-making increased YP self- esteem, and identity that increases resilience. This potentially counteracts the stigma associated with mental health which could encourage help-seeking behaviours. The art-making experience supported social connection (Gentle, 2018), combatting loneliness and isolation; which Corrigan (2014) demonstrated can minimise stigma. Thus in response to the first question of the study, art-making arguably has considerable therapeutic value. Additionally, the study showed in Stage 2 how the viewers also found an emotional connection through observing the artworks which helped them understand better the experiences of the YP and value their 
artistic abilities. This can also contribute to counteract the loneliness and anti-social behaviour associated with mental health as described by Junge (2019). The feedback reported back to three of the artists in Stage 3 increased their confidence as artists and contributed to their sense of self-worth as demonstrated in their positive reactions. This supports the work of McDonald and Mason (2015) that identified the arts as a means to belonging. Figure 2 below shows the findings that demonstrate the therapeutic aspect of art-making in this study.

Some of the therapeutic gains reported enhanced self-concept and artist identity that is described in the work of Fletcher and Lawrence (2018); Gentle (2018); \& Rubin (2008). These findings also complement research where art-making increased self-efficacy, selfworth, and self-expression (Gentle, 2018). These outcomes can help to increase resilience (Bolwerk et al., 2014), thereby reducing the impact of stigma.

With an emphasis on self-expression, creativity, enjoyment and social inclusion the arts are receiving increasing attention as a means of promoting health and mental health (Davies, Knuiman, \& Rosenberg, 2015). The importance of creative art in contributing to the YP's mental wellbeing is beginning to be understood and pursued as part of public health initiatives and interventions which aim to reduce stigma and promote recovery. The findings demonstrated some of the core principles of recovery and the use of art in tackling stigma.

\section{Recommendations for practice}

Arguably, findings here offer data to support the wider adoption of art based therapeutic activities to at least supplement or offer alternatives to medication and CBT aligned approaches. This is particularly important for rural and regional settings where service options are comparatively limited (Ivancic et al., 2018). Further research in the field that compares 'art as therapy' with an art therapy approach will help understand the differences and similarities in their approaches. This could support mental health services in providing 
relevant therapeutic interventions that offer alternatives or complimentary approaches. This is timely because the current use of medication (Blow, 2017) and CBT (James, James,

Cowdrey, \& Soler, 2015) that has not been shown to have the much anticipated therapeutic outcomes. 
Birhane, A. (2017). Descartes was wrong: 'a person is a person through other persons'. aeon. 07/04/2017. Retrieved from https://aeon.co/ideas/descartes-was-wrong-a-person-is-a-

Blow, Merson-through-other-persons . (2017). Antidepressants are not a 'quick fix' for children and young people with mental health problems. 299. doi:10.1211/PJ.2017.20203229

Bolwerk, A., Mack-Andrick, J., Lang, F. R., Dörfler, A., \& Maihöfner, C. (2014). How Art Changes Your Brain: Differential Effects of Visual Art Production and Cognitive Art Evaluation on Functional Brain Connectivity. PLoS ONE, 9(7), e101035. doi:10.1371/journal.pone. 0101035

Braun, V., \& Clarke, V. (2006). Using thematic analysis in psychology. Qualitative Research in Psychology, 3(2), 77-101. doi:10.1191/1478088706qp063oa

Breen, R., van de Werfhorst, H. G., \& Jæger, M. M. (2014). Deciding under Doubt: A Theory of Risk Aversion, Time Discounting Preferences, and Educational Decision-making. European Sociological Review, 30(2), 258-270. doi:10.1093/esr/jcu039

Brotherhood of St Laurence. (2018). An unfair Australia? Mapping youth unemployment hotspots. Retrieved from

http://library.bsl.org.au/jspui/bitstream/1/10573/1/BSL_Unfair_Australia_Mapping_y outh unemployment hotspots Mar2018.pdf

Corrigan, P. W. (2014). The stigma of disease and disability: understanding causes and overcoming injustices (Vol. 1st). Washington, D.C: American Psychological Association.

Davies, C., Knuiman, M., \& Rosenberg, M. (2015). The art of being mentally healthy: a study to quantify the relationship between recreational arts engagement and mental well-being in the general population. BMC public health, 16(1), 15.

Duran Diaz, A. P. (2018). From Universality to Particularities: Art Therapy and Third Spaces with New Immigrant Adolescents in Schools.

Edwards, D. (2014). Art therapy (2nd ed.). California: Sage.

Fletcher, T. S., \& Lawrence, S. S. (2018). Art Making and Identity Formation in Children and Adolescents with Differing Social Behaviors. Journal of Creativity in Mental Health, 13(2), 185-205. doi:10.1080/15401383.2017.1355290

Gentle, E. (2018). Autonomous Expression and Creative Connection: An exploration of artmaking with neurodivergent people in regional Australia. (PhD Doctorate), 
University of Sydney, Northern Clinical School. Retrieved from http://hdl.handle.net/2123/20416

Ivancic, L., Cairns, K., Shuttleworth, L., \& Welland, L. (2018). Lifting the weight: understanding young people's mental health and service needs in regional and remote Australia. Retrieved from https://apo.org.au/node/180271

James, A., James, G., Cowdrey, F., \& Soler, A., Choke. (2015). A. Cognitive behavioural therapy for anxiety disorders in children and adolescents. Cochrane Database of Systematic Reviews(2). doi:10.1002/14651858.CD004690.pub4

Jensen, S. Q. (2011). Othering, identity formation and agency. Qualitative studies, 2(2), 6378.

Junge, M. B. (2019). An Art Therapist's View of Mass Murders, Violence, and Mental Illness: Practical Suggestions for Helping Practitioners Find Support and Guidance in a Dangerous Practice: Charles C. Thomas, Publisher, Limited.

Kapitan, L. (2017). Introduction to art therapy research: Routledge.

Korstjens, I., \& Moser, A. (2018). Series: Practical guidance to qualitative research. Part 4: Trustworthiness and publishing. European Journal of General Practice, 24(1), 120124. doi:10.1080/13814788.2017.1375092

Kramer, E., \& Gerity, L. A. (2000). Art as Therapy: Collected Papers: Jessica Kingsley Publishers.

McDonald, J., \& Mason, R. (2015). Creative Communities: Regional Inclusion \& the Arts: Intellect, Limited.

National rural health alliance. (2017). Mental health in rural and remote Australia. Retrieved from https://ruralhealth.org.au/sites/default/files/publications/nrha-mental-healthfactsheet-dec-2017.pdf

Quinlan, R., Schweitzer, R. D., Khawaja, N., \& Griffin, J. (2016). Evaluation of a schoolbased creative arts therapy program for adolescents from refugee backgrounds. The Arts in Psychotherapy, 47, 72-78.

Rubin, J. A. (2008). Art Therapy Has Many Faces. Alexandria, VA; Pittsburgh, USA: Expressive Media.

Social Atlas. (2016). id Community Demographic Resources. Retrieved from Australia: https://atlas.id.com.au/coffs-harbour

South, J. (2006). Community arts for health: an evaluation of a district programme. Health Education, 106(2), 155-168. doi:doi:10.1108/09654280610650972

Stangl, A. L., Earnshaw, V. A., Logie, C. H., van Brakel, W., Simbayi, L. C., Barré, I., \& Dovidio, J. F. (2019). The Health Stigma and Discrimination Framework: a global, crosscutting framework to inform research, intervention development, and policy on health-related stigmas. BMC medicine, 17(1), 31 .

Venable, B. B. (2005). At-Risk and In-Need: Reaching Juvenile Offenders Through Art. Art Education, 58(4), 48-53.

WHO. (2017). Building resilience: a key pillar of Health 2020 and the Sustainable Development Goals. Retrieved from Italy: http://www.euro.who.int/ data/assets/pdf_file/0020/341075/resilience-report050617-h1550-print.pdf?ua $=1$ 
1

2

6

8

9

10

11

12

14

15

16

17

18

19

20

21

22

23

24

25

26

27

28

29

30

31

32

33

34

35

36

37

38

39

40

41

42

43

44

45

46

47

48

49

50

51

52

53

54

55

56

57

58

59

60

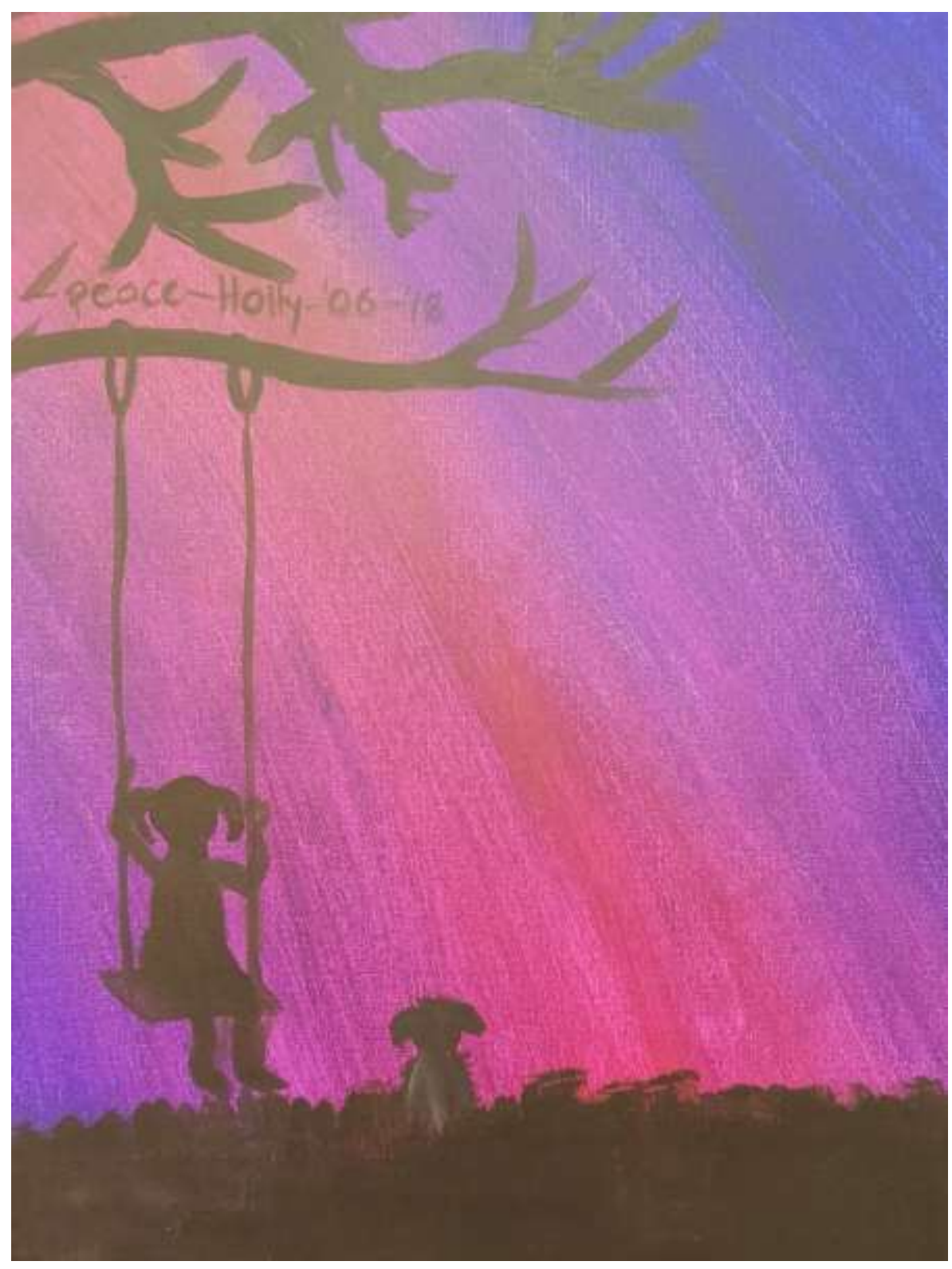




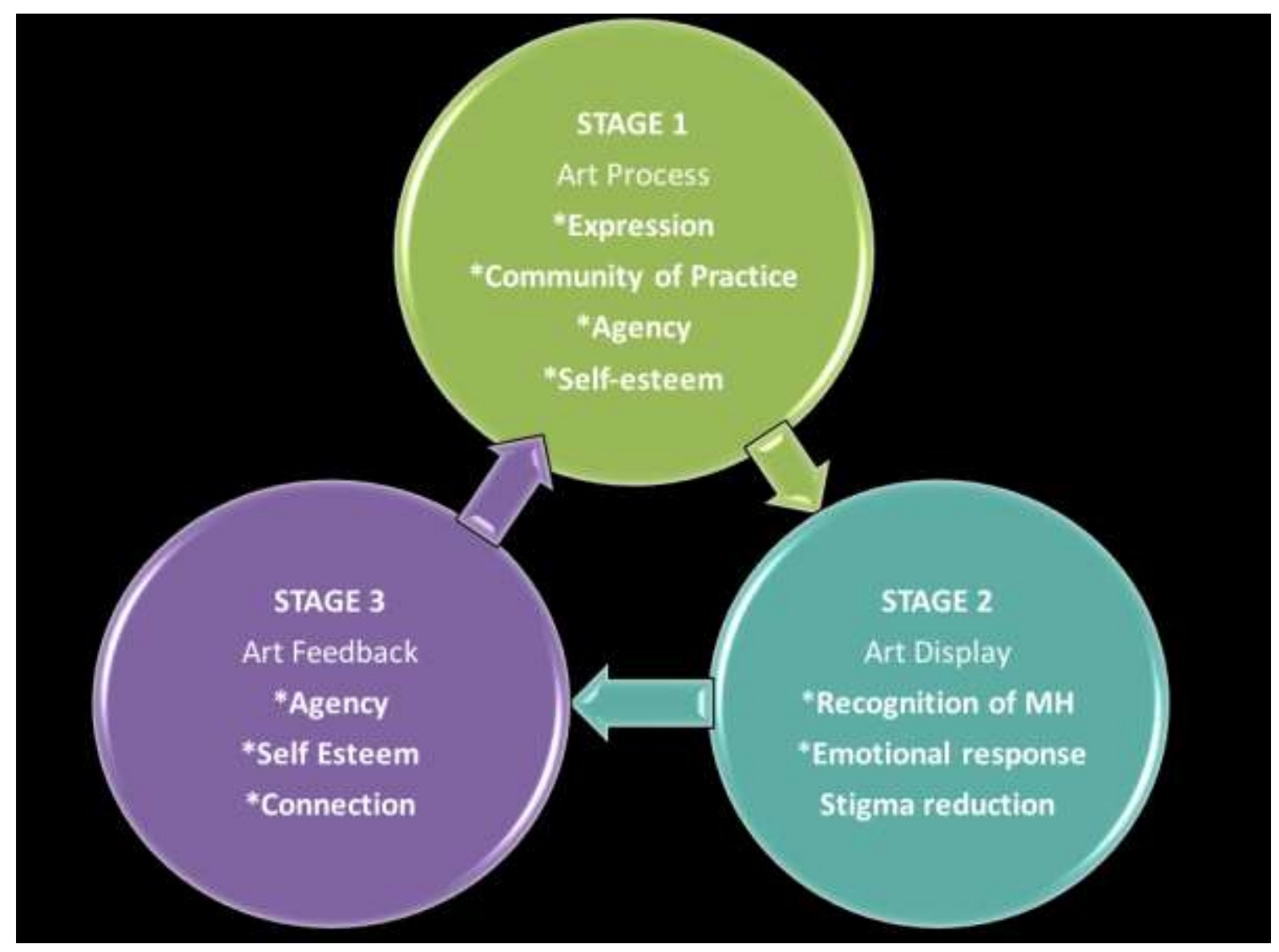




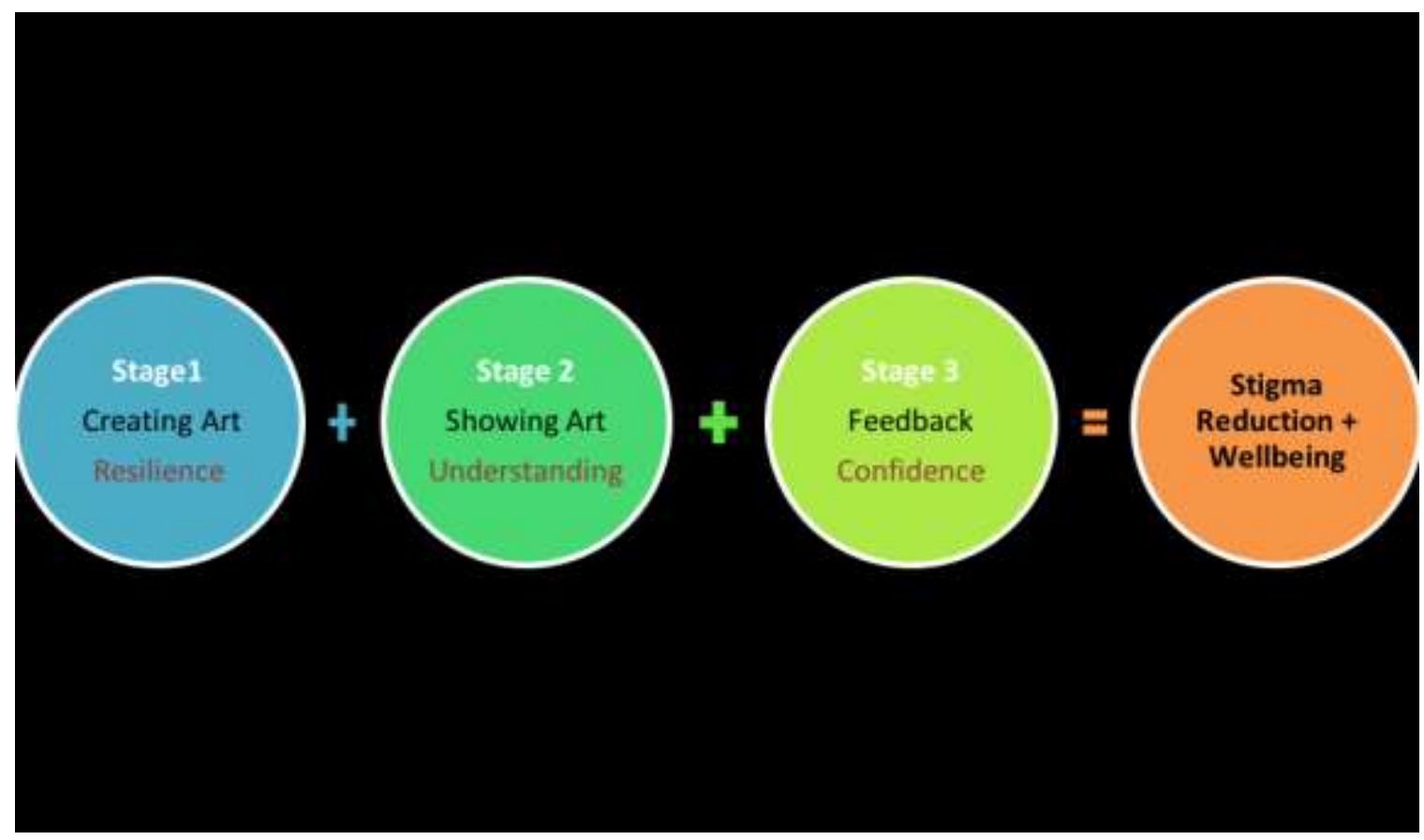


Artist and viewer demographics

\begin{tabular}{|l|l|l|l|l|l|l|l|l|l|l|l|l|}
\hline Stages & Key & $\mathbf{7 0 +}$ & $\mathbf{6 0}-$ & $\mathbf{5 0}$ & $\mathbf{4 0 -}$ & $\mathbf{3 0 -}$ & $\mathbf{2 0 -}$ & - & $\begin{array}{l}\text { Previous } \\
\text { exposure } \\
\text { to } \\
\text { mental } \\
\text { health }\end{array}$ & $\begin{array}{l}\mathbf{F}= \\
\mathbf{M}\end{array}$ & $\mathbf{N}=$ \\
$=$ & $\mathbf{5 9}$ & $\mathbf{4 9}$ & $\mathbf{3 9}$ & $\mathbf{2 9}$ & $\mathbf{2 0}$ & \\
\hline $\mathbf{1}$ (Artists) & $\mathrm{A} 1, \mathrm{~A} 2, \mathrm{~A} 3$ etc. & & & & & & 2 & 4 & & 6 & 0 & $\mathbf{6}$ \\
\hline $\mathbf{2}$ (Viewers) & $\mathrm{V} 1, \mathrm{~V} 2, \mathrm{~V} 3$ etc. & 5 & 12 & 1 & 2 & 2 & 1 & 2 & 18 & 16 & 9 & $\mathbf{2 5}$ \\
\hline $\mathbf{3}$ (Artists) & $\mathrm{A} 1, \mathrm{~A} 2, \mathrm{~A} 3$ etc. & & & & & & 1 & 1 & & 3 & & $\mathbf{2}$ \\
\hline
\end{tabular}

Table 1: Key and demographics of participants 